\title{
Covid 19 Situation Update in the Pediatric Population at EHU Oran
}

\author{
Djamila-Djahida Batouche ${ }^{1-3 *}$, Sid Ahmed Bakri ${ }^{1}$, Houcine Saddok ${ }^{1,2}$, \\ Dalila Ali-Amar ${ }^{2}$, Radia Dali-Youcef ${ }^{2,4}$, Douniazed Badsi ${ }^{2}$, Soulef-Amel \\ Saadi $^{2,5}$, Nadia-Faiza Benatta ${ }^{2}$ and Chafika Manouni ${ }^{2}$ \\ ${ }^{1}$ Pediatric and Neonatal Anesthesia - Intensive Care Unit EHU Oran, Algeria \\ ${ }^{2}$ Faculty of Medicine, Oran 1, Algeria \\ ${ }^{3}$ LERMER Research Laboratory, University Oran 1, Algeria \\ ${ }^{4}$ Bacteriology Service, EHU Oran, Algeria \\ ${ }^{5}$ Department of Biochemistry, EHU Oran, Algeria \\ *Corresponding Author: Djamila-Djahida Batouche, Pediatric and Neonatal \\ Anesthesia - Intensive Care Unit EHU Oran, Algeria.
}

Received: November 29, 2021

Published: December 20, 2021

(C) All rights are reserved by Djamila-Djahida

Batouche., et al.

\begin{abstract}
Today we have enough scientific publications showing that the majority of children infected with SARS-CoV-2 have a very favorable outcome. At present, morbidity in children remainslow and deathis an extremely rare event. The purpose of this article is to describe the pediatrics pecificities of covid 19 viral infection in children admitted to EHU Oran. Materials-methods:Were corded over a 10 -month period (March 1 to December 30,2020) the data using a pre-established survey sheet. We are included all children under the age of 17. For each patient, we are studied the socio-demographic parameters, the clinical signs at the consultation, the results of the PCR and the child's fate. Result: 302 children admitted with a mean age of $8.04 \pm 0.2$ years were the subject of the study The children were most often asymptomatic and very few children had presented a mildform (digestive pain, fever, cough, rhinorrhea), all were hospitalized with their parents, in different hospital service welcoming covid pathology at EHUO. The PCR was positive in $40 \%$ of the children. A multisystemic inflammatory syndrome in post covid 19 was noted in three patient. Conclusion:Children represent only a small percentage of cases of acute SARS-CoV-2 infection and are generally asymptomatic, or have mild to moderate symptoms.
\end{abstract} Keywords: Child; SARS-CoV-2; Mild Symptomatology; PIMS; Favorable Prognosis

\section{Introduction}

The spread of the novel coronavirus SARS-CoV-2, discovered in China in January 2020, led to a pandemic in Algeria as early as February. Children and adolescents under the age of 18 are much more rarely affected than adults and account for $1-5 \%$ of all cases described to date [1].

At present the morbidity in the child remains low, the pediatric forms of the disease are most often familial [2] moderate(fe- ver,cough, asthenia),even asymptomatic, death is an extremely rare event.

Objective: to describe the pediatric specificities of covid 19 viral infection in children admitted to EHU Oran.

\section{Materials and Methods}

- Type of study: This is a descriptive retrospective study.

- Framework of the study: It was conducted at the level of 
the Covid 19 tri-consultation unit at the EHUOran during the period from 1 March to 30 December 2020. Asymptomatic or symptomatic children, after the consultation at the triage level, were hospitalized with their parents in different departments of the EHUO taking care of the covid pathology.

- Participants in the study: We are included all children under the age of 17years old who consulted for proven or underknown symptomatology of covid 19.

15 incomplete clinical records were excluded from the study for lack of laboratory workup (C-reactive protein (CRP), blood count) and in 09 patients PCR with Sarcov2 could not be done due to lack of informed consent from guardians or parents.

\section{Data collection}

We analyzed the clinical records using a pre-established operating sheet grouping the following parameters: socio-demographic parameters, characteristics of the professions, development of COVID-19 symptoms, in the family and in children, underlying medical conditions and symptom characterization (presence of fever, cough, rhinorrhea, shortness of breath, among others).

Nasal, nasopharyngeal, oropharyngeal swab, nasotracheal, or blood samples tested positive for 2019-nCoV/SARS-CoV-2 nucleic acid by using real-time reverse-transcriptase polymerase chain reaction assay (RT-PCR). Chest imaging in symptomatic patients, \pm echocardiography if cardiac symptomatology.

Lab values including those for white blood cells, hemoglobin, lymphocyte count, CRP, CK-MB, D-Dimer, AST, ALT, urea, creatinine, $\mathrm{LDH}, \pm$ ferritin.

Statistical data were entered and analyzed using Microsoft Office Word 2007 software, and SPSS version 20. Quantitative variables that follow a normal distribution were described on average and those of non-normal distribution on a median. Pearson's chi-square test was used for the comparison of qualitative variables and the Yates test if any takes place. For numbers less than 5 , we used Fisher's test. The differences observed were considered significant for a $\mathrm{p}<0.05$ with a confidence interval of $95 \%$.

\section{Definition of clinical forms in children}

Asymptomatic form

Infection detected during screening or as part of tracing, without any symptoms.

\section{Mild form}

Fever - fatigue and/or upper respiratory tract involvement. No signs of lower respiratory tract infection: normal respiratory rate, no dyspnea, normal pulmonary auscultation, normal transcutaneous oxygen saturation $\left(\mathrm{SpO}_{2}\right)$, no radiological damage (if imaging was performed).

\section{Moderate form}

Symptoms related to damage to the lower respiratory tract, and/ or Decreased food intake (need for nutritional support), possible abnormalities related to COVID-19 on chest X-ray or chest ultrasound. $\mathrm{SpO}_{2}$ greater than or equal to $92 \%$ in ambient air.

\section{Severe form}

Algerian ministerial instruction number 10 of 22 April 2020.

\section{Polypnea}

FR $>70 /$ min in infants, $50 /$ min child $>1$ year FR $>70 / \mathrm{min}$ $\geq$ year) (after ruling out the effects of fever and crying).

Food ration $<50 \%$, Whining, Cyanosis, mottling of the extremities, apnea, agitation, Impaired consciousness, Acute dehydration. $\mathrm{SpO}_{2}$ under ambient air $<92 \%$.

\section{Critical form}

Paediatric Acute Respiratory Distress Syndrome (PARDS) and/or Multi-organ failure ( $>2$ organs) related to sepsis and/or Shock and/ or Coma [3].

\section{Results}

Of the 8897 consultations stopped on December 30, 2020. 302 children had been the subject of the study, an incidence of $3.39 \%$.

The children were aged between 1 month and 15 years (extreme 4 days-16 years), $52.8 \%$ were girls and $47.2 \%$ were boys (Figure 1).

The average age of the children was $8.04 \pm 0.2$ years. The distribution of cases among those under 16 years of age was as follows: $5 \%$ were aged $0-1$ years, $16 \%$ were $2-4$ years, $25 \%$ were $5-9$ years, $23 \%$ were $10-13$ years old and $31 \%$ were $14-16$ years old.

Clinical outcomes and diagnostic assessment

At the time of the consultation, there were very few clinical signs: 17 patients $(5,6 \%)$ had a cough, rhinorrhea, 39 children 


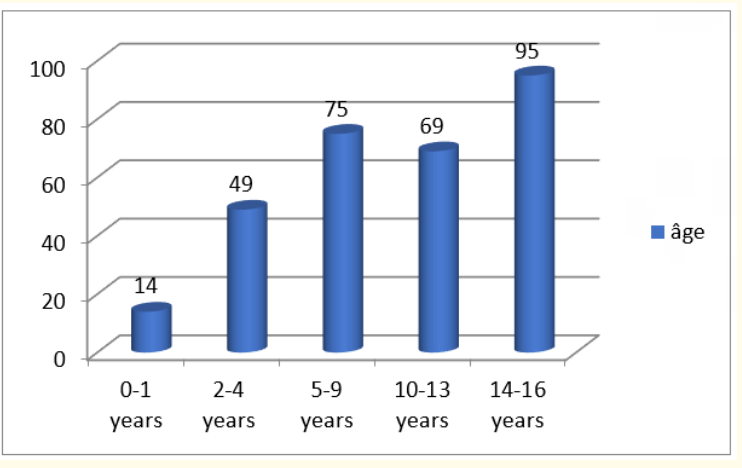

Figure 1: Graphical distribution by age group in the participants pédiatric population.Annual Reports).

$(12,9 \%)$ were febrile (Temperature between 37.9- 38.5) with nasal obstruction, $15(4,96 \%)$ children complained of digestive pain, diarrhea with loss of smell.

$8(2,64 \%)$ children were dyspneic and had a SPIO2 between 94 and $96 \%$ with a pulmonary focus at auscultation reinforced by foci of pulmonary condensation on the tele thorax.

The bacteriological result found; a positive SARS-CoV-2 PCR in $40 \%$ of children and negative in $52 \%$, distributed as follows: (Figure 2).

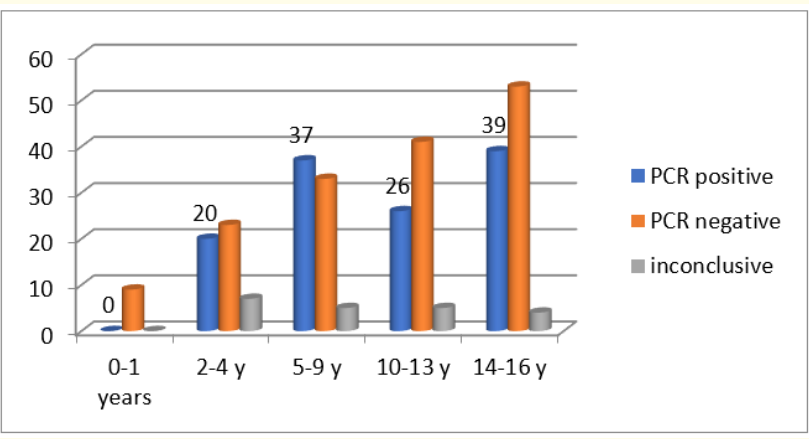

Figure 2: Biological result of SARS-CoV-2 PCR in the participants pediatric population.

Among the explorations, we found that the chest imaging was most often normal; ALT levels and myocardial enzymes achieved in symptomatic patients were not significantly abnormal. Cardiovas- cular, hepatic and renal functions were almost always normal except in 2 patients. Likewise, blood tests are little disturbed (normal or temporarily deregulated reactive $\mathrm{C}$ protein, The median WBC ranged from 6 to $9.45 \times 10^{9} / \mathrm{L}$. A total of 15 out of 302 patients $(4,96 \%)$ with biological results had a lymphocyte count of $<1.5$ $\left.\times 10^{9} / \mathrm{L}\right)$.

Therapeutic intervention and outcome (Table 1).

The median length of symptomatic disease was 7 days, with a minimum of 2 and a maximum of 14 days. Children with little symptoms with a febrile viral infection of the upper respiratory tract with a PCR SARCOV 2 positive were treated with antibiotics in per os type amoxicillin or azithromycin depending on age, antipyretic (prodafalgan type) according to the health protocol (Instruction-N-10-DGSSRH-DU-22-Avril-2020-Relative-to-the-management-of-cases-Covid-19-in-the-child).

All the children had progressed well and put out on after 7-10 days of treatment.

An 07-year-old patient was hospitalized at the EHU Oran pediatric intensive care unit for a Pediatric multisystemic inflammatory syndrome associated with Covid-19 (PMIS-C). The SARCOV 2 antigen test was positive.

The child was intubated, ventilated, treated with inotropic support for 03 days, $2 \mathrm{~g} / \mathrm{kg}$ intravenous immunoglobulins and $50 \mathrm{mg} /$ $\mathrm{kg}$ acetylsalicylic acid. His evolution was favorable at the end of the 7 th day of hospitalization.

Two other children were hospitalised with PIMS-C complicating cardio-renal disease which requiring inotropes vasopressors and volume loading, intravenous infusion of immunoglobulins, corticosteroid therapy supplemented if necessary by pericardial drainage and replacement renal therapy ( 1 case). This children fully recovered within a week, some of them later developed coronary artery dilation or aneurysm.

\section{Discussion}

Our hospital structure has taken care since the beginning of the pandemic the covid pathology where the sorting is done at the level of the covid unit specially arranged during the pandemic The children were hospitalized in the services hosting the pathology 


\begin{tabular}{|c|c|c|c|c|}
\hline $\mathrm{N}$ cases $(\%)$ & Symptoms & Admission service & Treatment & Outcome \\
\hline $39(12,9)$ & Fever et/ou headache & Médical & Antipyretic type prodafalgan & $\begin{array}{c}\text { Favorable outcome on aver- } \\
\text { age over } 4 \text { days }\end{array}$ \\
\hline $1(0,3)$ & PIMS & Intensive care unit & $\begin{array}{c}\text { VA, SH } \\
\text { IV IG } \\
\text { NSAI }\end{array}$ & Favorable after the $7^{\text {th }}$ day \\
\hline $2(0,6)$ & $\begin{array}{l}\text { PIMS-C complicating } \\
\text { cardio-renal desease }\end{array}$ & Intensive care unit & $\begin{array}{c}\text { CS } \\
\text { IV IG } \\
\text { VE } \\
\text { PD (2 cases }) \\
\text { RRT (1 case })\end{array}$ & $\begin{array}{l}\text { Fully recovered within a } \\
\text { week }\end{array}$ \\
\hline
\end{tabular}

Table 1: Therapeutic intervention and outcome in symptomatic children.

MA: Mechanical Ventilation; IS: Inotropic Support; IV Ig: Intravenous Immunoglobulin; NSAI: Non-steroidal anti-inflammatory Drugs; CS: Corticosteroids; VE: Volume Loading; PD: Pericardial Drainage; RRT: Replacement Renal Therapy.

COVID 19 with their parents (contact subjects or proven subjects). The source of contamination of the child is most often intra-family. Several studies report that a high proportion of pediatric cases had a history of exposure to an adult case in the family or to another adult [2].

Data from different countries confirmed the lower frequency of covid infection in children and its lower severity. The infection is most often mild responsible for unseemly specific clinical signs [4-7].

In one series, some children nevertheless have gastrointestinal symptoms (abdominal pain nausea,vomiting and diarrhea) [7].

Across all ages, a meta-analysis estimated that diarrhea affects just over $10 \%$ of patients ( $2 \%$ to $50 \%$ of cases depending on the studies) before, during or after respiratory symptoms [8].

In the pediatric population of our study, we found on biochemical examination: few disturbed blood tests (normal or temporarily deregulatedC-reactive protein;liver and kidney function are almost always normal, unlike what is observed in their sick parents or grandparents. Neutrophil polynucleosis and lymphopenia was common in $6 \%$ of symptomatic patients.

The SARS-CoV-2virus test by PCR was performed in young infants and children, $40 \%$ of whom were positive. There was no significant difference between clinical symptomatology and PCR outcome $(p=0.0045)$.

A large retrospective study of 171 patients under 16 years of age, diagnosed by RT-PCR on nasopharyngeal swab, found a median age of 6.7 years. Contamination was 90\% intra-familial. Lymphopenia (3.5\%) appeared to be less common than in adults. $65 \%$ of patients developed radiological pneumonitis, in the form of frosted glass images, $7 \%$ of which had no clinical signs. Fifteen percent of patients had no clinical signs or radiographic abnormalities [9].

In this study, the chest scan was not indicated, even if hospital management was considered during the $1^{\text {st }}$ wave of the pandemic, the children had not presented any severe form of Covid pathology. 
Symptomatic or non-symptomatic children were placed in isolation-quarantine in the hospital, with their parents in the various departments. This forced confinement of children, the closure of schools, had consequences in particular in terms of reduced physical activity. Some children in some departments had experienced major emotional and relational disturbances involving psychologists from the EHU Oran.

Severe and critical forms are rare in the literature. No critical forms during hospitalization were noted. Chinese and Italian epidemiological data on thousands of cases initially reported very few ICU admissions and no deaths. Since then, rare additional cases of pediatric deaths have been reported, including fewer than 10 children, a priori with associated comorbidities. Among infected children, young age has been described as a risk factor for severity [1,11-15].

In this study, the children did not exhibit comorbidity during hospitalization.

In Algeria there are no published case series relating to the admissions of children and the prognosis of these children to intensive care. Nevertheless, 02 deaths were noted from the Algerian press $[17,18]$.

In Europe and the United States, after the pandemic the appearance of a potentially serious disease was declared in children who tested positive for Covid-19. It is an inflammatory disease called «multi-inflammatory syndrome in children» (MIS-C) by the US health authorities [19]. It resembles disease, and is nicknamed Kawasaki-like, or PIMS (pediatric multisystemic inflammatory syndrome) [20].

Given the epidemiological context, the clinician should discuss the diagnosis of MIS-C in any child with persistent fever without a clinical focus and any fever associated with an alteration in general condition coinciding with recent exposure to SARS-CoV-2 should be suspected of MIS-C.

Three chidren were hospitalized in pediatric intensive care unit at EHU Oran, for a post-covid multisystemic inflammatory syndrome (PIMS) that had evolved favorably.

\section{Limitations of the Study}

This work has some limitations to the generalization of deductions including the retrospective and documentary aspect of data collection likely to lose necessary information that does not appear in the files.

\section{Conclusion}

Children account for only a small percentage of acute SARSCoV-2 cases and, in general, they are asymptomatic, or they experience mild to moderate symptoms such as fever, dry cough and fatigue, as well as abdominal pain and diarrhea in some cases. The infected children were infected by an adult in their entourage.

The severity and mortality rate of infection in young children is lower than in adults.

An acute inflammatory disease that has a temporal link to COVID-19 in a few pediatric patients has been described in theliterature. Nevertheless, pathology is still unknown with unexpected repercussions in children, hence the interest in broadening the range of publications in order to compare our results with other learned societies to identify a better approach in the pediatric population.

\section{Our Recommendations}

We wish to Set up a "Covid CHILD" network to enable the coordination of a survey with all Algerian Pediatric intensive care unit cases in the first 48 hours of the patient's admission to intensive care with follow-up on D7 to know the clinical evolution of the child, and to send the information to Algerian Public Health, to the Ministry to take, the where appropriate, health measures or additional surveillance means.

\section{Sources of Funding}

None.

\section{Disclosure of Interest}

The authors declare that they have no competing interest.

\section{Bibliography}

1. Wu Z and McGoogan JM. "Characteristics and important lessons from the coronavirus disease 2019 (COVID-19) outbreak in China: summary of a report of 72,314 cases from the Chinese Center for Disease Control and Prevention". Journal of the American Medical Association 323 (2020): 129-142.

2. Meng-Yao Zhou and Xiao-Li Xie. "From SARS to COVID-19: What we have learned about children infected with COVID-19". International Journal of Infectious Diseases 96 (2020): 710-714. 
3. Pediatric Acute Lung Injury Consensus Conference Group. "Pediatric acute respiratory distress syndrome: consensus recommendations from the pediatric acute lung injury consensus conference". Pediatric Critical Care Medicine 16 (2015): 428-439.

4. "Zimmermann and Curtis". The Pediatric Infectious Disease Journal 39.5 (2020).

5. Ludvigsson Jonas F. "Systematic review of COVID-19 in children shows milder cases and a better prognosis than adults". Acta Paediatrica 109 (2020): 1088-1095.

6. Qiu H., et al. "Clinical and epidemiological features of 36 children with coronavirus disease 2019 (COVID-19) in Zhejiang, China: an observational cohort study". Lancet Infectious Disease 20.6 (2020): 689-696.

7. Yuanzhe Li., et al. "Insight into COVID-2019 for pediatricians". Pediatric Pulmonology 55.5|'(2020): E1-E4.

8. Ferdinando D’Amico., et al. "Diarrhea during COVID-19 infection: pathogenesis, epidemiology, prevention and management". Clinical Gastroenterology and Hepatology 18.8 (2020): 1663-1672.

9. Lu X., et al. "SARS-CoV-2 Infection in children". The New England Journal of Medicine (2020).

10. Bucher K. "Coronavirus Disease 2019 (COVID-19) in Italy". Journal of the American Medical Association 323.14 (2020): 1335.

11. Ambrosioni J., et al. "Epidemiology of viral respiratory infections in a tertiary care centre in the era of molecular diagnosis, Geneva, Switzerland, 2011-2012". Clinical Microbiology and Infection 20 (2014): 578-584.

12. Liu W., et al. "Detection of Covid-19 in Children in Early January 2020 in Wuhan, China". The New England Journal of Medicine 382 (2020): 1370-1371.

13. Dong Y., et al. "Epidemiological Characteristics of 2143 Pediatric Patients With 2019 Coronavirus Disease in China”. Pediatrics 145.6 (2020): e20200702.

14. Leeb RT., et al. "COVID-19 Trends Among School-Aged Children - United States, March 1-September 19, 2020". Morbidity and Mortality Weekly Report 69.39 (2020): 1410-1425.
15. Swann OV., et al. "Clinical characteristics of children and young people admitted to hospital with covid-19 in United Kingdom: prospective multicentre observational cohort study". BMJ 370 (2020): m3249.

16. Bellino S., et al. "COVID-19 Disease Severity Risk Factors for Pediatric Patients in Italy". Pediatrics 146.4 (2020).

17. https://www.elwatan.com/edition/actualite/sidi-slimane-lapopulation-entre-stupeur-et-deni-apres-lannonce-du-decesdu-premier-cas-de-covid-19-enfant-dalgerie-08-04-2020

18. https://www.algerie360.com/covid-19-deces-dun-bebe-de11-mois-a-batna/

19. Centers for Disease Control and Prevention, Health Alert Network (U.S.). "Multisystem Inflammatory Syndrome in Children (MIS-C) Associated with Coronavirus Disease 2019 (COVID-19)" (2020).

20. McCrindle BW and Manlhiot C. "SARS-CoV-2-related Inflammatory Multisystem Syndrome in children: different or share etiology and pathophysiology as Kawasaki disease?" Journal of the American Medical Association 324.3 (2020): 246-248.

\section{Assets from publication with us}

- Prompt Acknowledgement after receiving the article

- Thorough Double blinded peer review

- Rapid Publication

- Issue of Publication Certificate

- High visibility of your Published work

Website: www.actascientific.com/

Submit Article: www.actascientific.com/submission.php

Email us: editor@actascientific.com

Contact us: +919182824667 